\title{
Morphological plasticity in a gorgonian coral (Briareum asbestinum) over a depth cline
}

\author{
J. M. West, C. D. Harvell, A.-M. Walls* \\ Section of Ecology and Systematics, Cornell University, Ithaca, New York 14853, USA
}

\begin{abstract}
We document pronounced variation in whole colony morphology as well as polyp density, sclerite morphology, egg size, and egg number between colonies of Briareum asbestinum (Gorgonacea) from shallow and deep reefs. Colonies from shallow $(5 \mathrm{~m})$ sites are shorter and stouter than colonies from deep $(35 \mathrm{~m})$ sites, with a greater density of polyps, greater number of eggs per polyp, and larger eggs than their deep counterparts; in addition, deep colonies contain longer sclerites than shallow colonies. Through a transplant experiment, we demonstrate that variation in morphology of colonies and sclerites between shallow and deep reefs is due, in part, to environmental effects. The stout colonies of shallow reefs become thinner in deeper water and develop longer sclerites and fewer polyps. Deep-water colonies become stouter and develop more polyps when moved to shallow water. The shifts in sclerite morphology may have consequences for resistance to predation. Cyphoma gibbosum (Gastropoda) avoids artificial foods invested with deep water relative to shallow water sclerites.
\end{abstract}

\section{INTRODUCTION}

Analyses of causes of variation in traits along habitat clines have contributed to understanding the evolution of variant forms and functions (Antonovics 1976, Briggs \& Walters 1988). In marine systems, depth clines provide such a gradient for examining causes of variation since physical and biological factors such as light level (McCloskey \& Muscatine 1984, Miles 1991), wave exposure (deWeerdt 1981) and predator levels (Hay \& Goertemiller 1983, Hay et al. 1983) change drastically over distances as short as $10 \mathrm{~m}$.

Colonial invertebrates are well known for phenotypically plastic responses to environmental change. Variation in colony form or physiology with depth has been demonstrated by Wijsman-Best (1974), Veron \& Pichon (1976), Dustan (1979), Davies (1980), Foster (1980), and McCloskey \& Muscatine (1984). In these cases, variation in colony form among habitats was believed to be due to phenotypic plasticity (Wijsman-

\footnotetext{
- Present address: Laboratory of Ecological Zoology, Department of Biology, University of Turku, SF-20500 Turku, Finland
}

Best 1974, Dustan 1979, Davies 1980, McCloskey \& Muscatine 1984) although colonies were actually transplanted among habitats only in the studies of Veron \& Pichon (1976) and Foster (1980). Presumed shifts in morphology have been sufficient to cause errors in taxonomy (Wijsman-Best 1974, Veron \& Pichon 1976). However, recent genetic studies indicate that some morphological variants of tropical bryozoans (Jackson \& Cheetham 1990) and corals (Knowlton et al. 1992) originally assumed to be environmentally induced 'morphotypes' may actually be true sibling species.

The gorgonian soft coral Briareum asbestinum is morphologically variable among habitats in the Caribbean. Unlike most other gorgonian corals that are distributed over narrow depth ranges, $B$. asbestinum is widely distributed from shallow (1 to $5 \mathrm{~m}$ ) sites to deep reefs at $40 \mathrm{~m}$ (Bayer 1961, Kinzie 1971). It occurs in both encrusting and erect forms in shallow water. Since the 2 forms are genetically differentiated in habitats in which they co-occur (D. Brazeau \& C. D. Harvell unpubl.), we consider only the erect form here. Erect colonies from different habitats vary in morphology; shallow-water colonies are short, stout and some- 


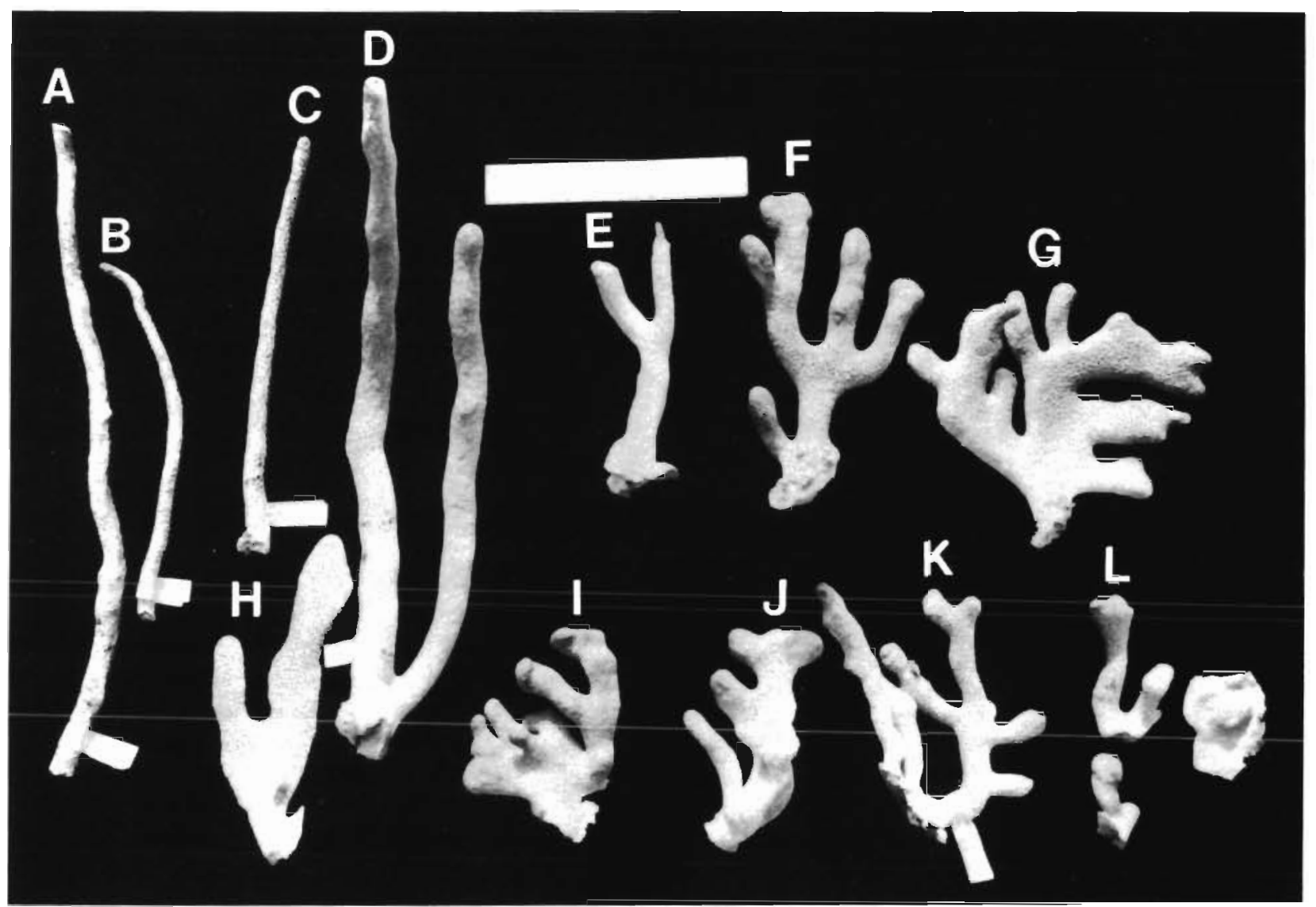

Fig. 1. Briareum asbestinum. Variation in colony morphology. Deep colonies A to C (from $35 \mathrm{~m}$ ) are long, slender, and less branched compared to shallow colonies D to $\mathrm{L}$ (from $5 \mathrm{~m}$ ), which are shorter, stouter and more branched. Scale bar $=6$ in (ca $15.2 \mathrm{~cm}$ )

times branched while deep-water colonies are long, slender and unbranched (Fig. 1). The cause of the morhological variation among $B$. asbestinum populations is unknown; both genotype and environment could play roles in the observed variation. A strong genetic component might be expected because the large, yolk-filled larvae of this species are brooded on the maternal colony and appear to be locally dispersed and philopatric (Brazeau \& Lasker 1990). B. asbestinum can also reproduce asexually by fragmentation; branch fragments that break off can reattach to the substrate and grow as new colonies (Brazeau 1989). Thus, the variant colony forms observed over a depth cline could be the result of a local dispersal pattern coupled with strong variation in local selection regimes.

In this study, we describe the morphologies of Briareum asbestinum colonies from shallow and deep sites. In addition to overall colony form, we examined polyp density, egg size and number, and sclerite morphology. To determine whether the environment contributes to variation in colony morphology between depths, we implemented a transplant experiment. The effect of sclerite length on tissue palatability was tested for 1 predator, Cyphoma gibbosum (Gastropoda), using an artificial food assay.

\section{METHODS}

Comparative morphology analysis: shallow versus deep. Morphological variation between shallow and deep Briareum asbestinum colonies was studied in 1988 at Mama Rhoda Reef, Chub Cay and at Rum Cay, Bahamas. Nineteen colonies were collected from shallow $(5 \mathrm{~m})$ reefs, and 24 colonies were collected from deep $(35 \mathrm{~m})$ reefs. Colonies from shallow water were selected on the basis of morphology and size: only large (>150 $\mathrm{mm}$ ) colonies of the most common shallow water morphology (Fig. 1D) were collected. Deep colonies were more rare, so all colonies $>150 \mathrm{~mm}$ in length were collected during the dive; these were all of the unbranched form (Fig. 1A to C). The total length and the width $10 \mathrm{~cm}$ below the tip of each 
colony was measured to the nearest millimeter using calipers.

Sclerite length was analyzed from 7 shallow $(8 \mathrm{~m})$ and 5 deep $(33 \mathrm{~m}$ ) colonies collected from Cane Bay, St. Croix, U.S. Virgin Islands in January 1988. Combined cortex and axis sclerites were isolated from

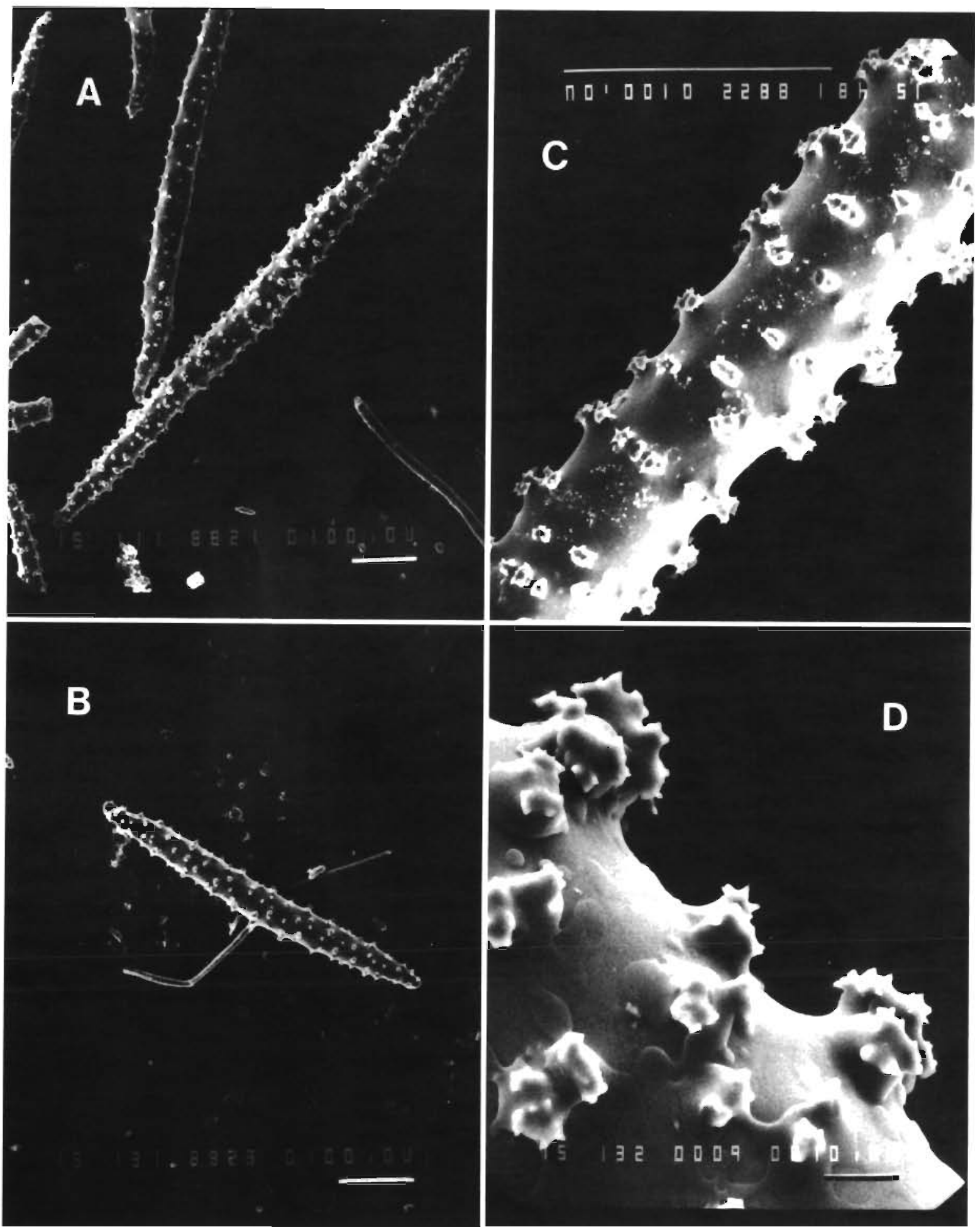

Fig. 2. Briareum asbestinum. Scanning electron micrographs of the longest spindle sclerites from the outer cortex of colonies from shallow $(5 \mathrm{~m}$ ) and deep (35 m) reefs (Chub Cay, Bahamas). Sclerite from (A) deep colony (35 $\mathrm{m}$ ) and (B) shallow colony $(5 \mathrm{~m})$. (C \& D) Higher magnification of deep sclerites. Scale bar $(A$ to $C)=100 \mu \mathrm{m} ;(D)=10 \mu \mathrm{m}$ 
approximately $1 \mathrm{~cm}^{2}$ pieces of Briareum asbestinum isolated $10 \mathrm{~cm}$ below the tip; the tissue was dissolved in a $50 \%$ Clorox $^{\oplus}$ solution for 1 to $3 \mathrm{~h}$, and the sclerites were rinsed with distilled water. Scanning electron microscopy (SEM) revealed no erosion of the sclerites by the Clorox $^{\otimes}$ (Fig. 2). We also measured sclerites isolated from separated axis (central, purple region of the colony) and cortex (outer, polyp-containing region) tissue approximately $10 \mathrm{~cm}$ below the tips of 3 colonies originating from each of the shallow and deep sites. For this analysis, we measured length because previous studies have suggested length to be an important character affecting deterrence of gorgonians to predators (Harvell \& Suchanek 1987). Three microscope slides of sclerites were prepared from each colony, and 3 frames were subsampled at $10 \times$ magnification from each slide. To estimate differences in maximum sclerite length, we measured the 5 longest sclerites in each frame using an Imaging Technologies Framegrabber and software custom-designed by W. Haake. A mean maximum sclerite length was calculated for each colony and used as the dependent variable in the statistical analysis.

For fecundity estimates, we measured polyp density, oocyte density, and oocyte diameter for 7 shallow and 9 deep female colonies (identified by the presence of internal oocytes visible within the colony tissue) collected from the Chub Cay population in the Bahamas. We collected the colonies between 8 and 10 June 1989, just prior to the peak in annual spawning for this species. From each colony, 3 cross sections were cut approximately $10 \mathrm{~cm}$ below the growing tip [Brazeau (1989) has shown the highest density of brooded embryos to be in mid-regions of colonies]. The number of oocytes per polyp and polyps per cross section were counted for each cross section; the diameters of 3 oocytes per cross section were measured with an ocular micrometer (10X magnification) for a total of 9 oocytes measured per colony. All measures of error reported are 1 standard error of the mean.

Transplant experiment. To assess whether environment contributes to depth-related variation in sclerite morphology and colony form in Briareum asbestinum, a reciprocal transplant experiment was conducted in St. Croix from January to June 1989. Forty-eight branches (approximately $10 \mathrm{~cm}$ in length) originating at $10 \mathrm{~m}$ were collected; 24 were transplanted to $33 \mathrm{~m}$ and 24 were returned to $10 \mathrm{~m}$. This procedure was repeated for 48 deep branches, such that each of 2 transplant sites ( 10 and $33 \mathrm{~m}$ ) received 24 colonies that had originated at that site and 24 colonies that had been moved from the opposite site. A third, deeper transplant location $(41 \mathrm{~m})$ received an additional 24 colonies transplanted from the shallow $(10 \mathrm{~m})$ site.

To minimize the stress experienced by the transplant colonies, the entire reciprocal transplant was set up in $1 \mathrm{~d}$. The colonies were transported to an intermediate depth of $20 \mathrm{~m}$ where they were loaded onto transplant racks within $30 \mathrm{~min}$. Each rack consisted of a $30.0 \times$ $23.0 \times 2.5 \mathrm{~cm}$ acrylic plate with 12 (2 rows of 6$)$ recessed wells into which the base of a colony fitted. Each colony was secured via cushioned cable ties to an upright, acrylic support glued inside the recessed well; an individually coded label was attached to each upright to identify the colony. Shallow and deep colonies were alternated on the racks.

After all colonies were in place, each row of colonies was videotaped underwater, including a scale bar, to allow later, initial size comparisons with image analysis. Four of the racks were then transported to the deep $(33 \mathrm{~m})$ site and 4 to the shallow $(10 \mathrm{~m})$ site. The additional group of 24 shallow colonies on 2 racks were transplanted to the very deep $(41 \mathrm{~m})$ site the following morning. Each rack was affixed to a stand that elevated it approximately $1.5 \mathrm{ft}$ (ca $0.46 \mathrm{~m}$ ) above the substrate to minimize colony damage by benthic predators. To discourage disturbance by fishes, each rack was provided with a transparent, large (1 in, ca $2.54 \mathrm{~cm}$ ) mesh nylon roof. The colonies were checked monthly (a total of 5 times), at which time the roofs were brushed clean of algae and the colonies checked for the presence of predators. The group of 24 shallow colonies transplanted on 2 racks to $41 \mathrm{~m}$ were checked only at the end of the experiment.

After $6 \mathrm{mo}$, all of the racks were retrieved to $10 \mathrm{~m}$ and were again videotaped in situ for image analysis of final heights. The initial and final colony heights and the initial colony widths of the transplants were determined from the videotapes using image analysis. Because polyps were sometimes extended and affected the precision with which we could measure widths with image analysis, the final tip widths $11 \mathrm{~cm}$ below tip) were measured (with calipers) from only the undamaged preserved specimens. The polyp density of each preserved colony was also measured by counting and averaging the number of polyps per $0.625 \mathrm{~cm}^{2}$ in 3 replicate quadrats on the upper third of the colony but at least $1 \mathrm{~cm}$ below the growing tip.

Methods similar to those described in the 'Comparative morphology' section were used to determine maximum sclerite lengths for the colonies involved in the transplant experiment. To ensure that we only sampled tissue produced after transplantation, sclerites were isolated from the cortex region of the growing tip (approximately 0.5 to $1 \mathrm{~cm}^{2}$ tissue); only colonies with undamaged tips were used. Sclerites were again isolated using a $50 \% \mathrm{Clorox}^{\otimes}$ solution, and the lengths of the 5 longest sclerites from each of 3 frames from each of 3 slides were measured and averaged. 
The data from the transplant experiment were analyzed in 2 groups. The reciprocal transplant group contained 4 treatments: SS, shallow colonies transplanted to the shallow site; $\mathrm{SD}$, shallow colonies transplanted to the deep site; DS, deep colonies transplanted to the shallow site; and DD, deep colonies transplanted back to the deep site. The other group contained colonies originating only in shallow water and transplanted to the shallow (SS), deep, (SD), and even deeper (SDD) site. In both groups, the same variables were measured on the colonies including colony height, tip width, polyp density and sclerite length. Because different measuring techniques were employed for different variables and because sample sizes were not balanced, we used univariate statistical analysis

Artificial food assays. To examine a predator-related consequence of sclerite variation between shallow and deep Briareum asbestinum colonies, sclerites were incorporated into a carageenan-based artificial food that could be fed to Cyphoma gibbosum, one of the most destructive predators of $B$. asbestinum (Kinzie 1971 ). Each batch of food was made to a volume of 20.5 $\mathrm{ml}(15 \mathrm{ml}$ water, $0.5 \mathrm{ml}$ carageenan, $5 \mathrm{ml}$ Plexaurella dichotoma aqueous extract); sclerites from shallow vs deep colonies were added to designated batches of food to make up $70 \%$ of the volume. P. dichotoma extract was used as a feeding attractant to $C$. gibbosum (the molluscs would not feed readily on the artificial food without the $P$. dichotoma extract added). For each feeding trial, the same amount of $P$. dichotoma extract from the same colony was used in the paired batches of food; hence, the extract should have had no effect on the outcome of the trials. So that the attractants would not be destroyed by heating, $P$. dichotoma extract was

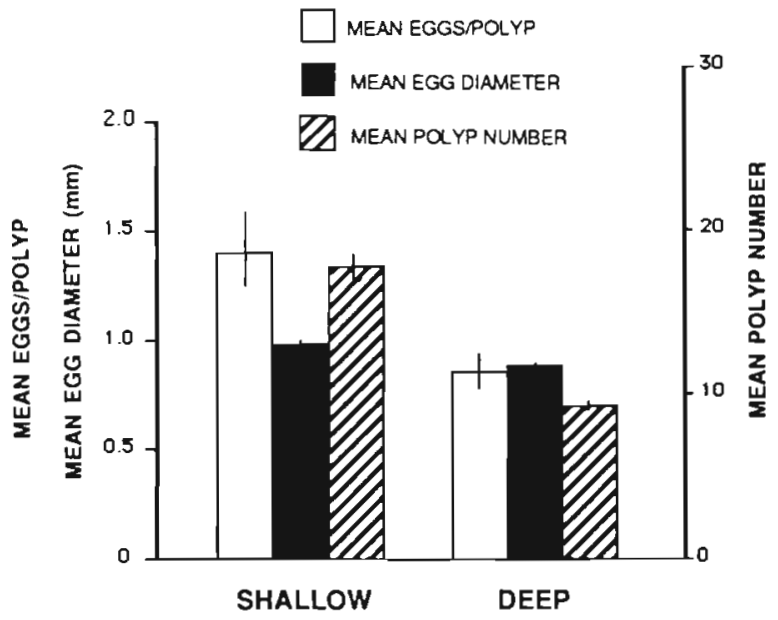

Fig. 3. Briareum asbestinum. Mean polyp number, and mean diameter and density of oocytes from deep ( 33 to $41 \mathrm{~m}$ ) and shallow ( 3 to $7 \mathrm{~m}$ ) colonies (Chub Cay and Rum Cay, Bahamas). Oocytes were sampled from colonies just prior to spawning in June 1989 added after the artificial food was first liquified through microwaving and partially cooled.

The liquid food was poured over tie-downs around which it hardened to produce $2.0 \times 1.0 \times 0.25 \mathrm{~cm}$ baits For the bioassay trials, 26 pairs of Cyphoma gibbosum (first trial) and 20 pairs of C. gibbosum (second trial) were housed in $9 \times 9 \times 6 \mathrm{~cm}$ perforated plastic vessels that were submerged in a shipboard aquarium with running seawater. For each trial, a pair of baits (shallow sclerites vs deep sclerites) was tethered to the bottom of the vessel, and the C. gibbosum were allowed to feed for $24 \mathrm{~h}$ or until approximately one half of one bait in the vessel was consumed. Each trial was scored blind by 2 operators who estimated the percentage of each bait consumed. The mean of the 2 estimates for each bait was used as the statistic (on average, the estimates of the 2 operators differed by less than $2.5 \%$ ) and pairwise comparisons were tested for significance using the Mann-Whitney $U$-test; vessels in which the C. gibbosum did not feed at all during the course of the assays were excluded from the analysis.

\section{RESULTS}

\section{Comparative morphology analysis}

The correlation between colony length and width was very low for both shallow $\left(\mathrm{r}^{2}=0.008\right)$ and deep colonies $\left(r^{2}=0.015\right)$. However, the 19 shallow colonies measured were significantly stouter and shorter as seen by a larger width/length ratio $(0.063 \pm 0.004)$ than the 24 deep $(0.029 \pm 0.003)$ colonies (unpaired $t$-test, $p<0.001)$. These morphological differences are readily recognized (Fig. 1) and have been observed at all sites where we studied the shallow and deep Briareum asbestinum throughout the Bahamas and St. Croix.

Sclerite morphology varied significantly between the shallow and deep colonies from Cane Bay, St. Croix. The combined axis and cortex sclerites from the 7 shallow $(8 \mathrm{~m})$ colonies were significantly shorter than the sclerites from the 5 colonies originating from a deep (33 m) site (unpaired $t=2.52, \mathrm{df}=10, \mathrm{p}=0.03$ ). The mean maximum sclerite length of the shallow colonies was $0.64 \pm 0.02 \mathrm{~mm}$ as opposed to the mean maximum length of $0.73 \pm 0.03 \mathrm{~mm}$ of the deep colonies; this mean difference of $.009 \mathrm{~mm}$ represents 12 to $14 \%$ of the total mean sclerite length. Although we compared cortex and axis sclerites from only 3 shallow and 3 deep colonies, the differences still approached the traditional $5 \%$ threshold of statistical significance (ANOVA, $F=3.96, p=0.053$ ) between the 4 groups tested for sclerite length: (1) shallow axis sclerites: 0.66 $\pm 0.02 \mathrm{~mm}_{i}(2)$ deep axis sclerites: $0.74 \pm 0.04 \mathrm{~mm}$; (3) shallow cortex sclerites: $0.60 \pm 0.04 \mathrm{~mm}$; and (4) deep 
cortex sclerites: $0.73 \pm 0.03 \mathrm{~mm}$. Cortex (but not axis) sclerites from shallow colonies were significantly shorter than the corresponding sclerites from deep colonies $(p<0.05$, Fisher Protected Least Significant Differences, PLSD). Since depth-related variation in sclerites only occurred in cortex tissue, only cortex sclerites were analyzed in subsequent experiments.

The reproductive traits measured for each colony were the mean number of oocytes per polyp and the mean oocyte diameter for both shallow and deep colo-
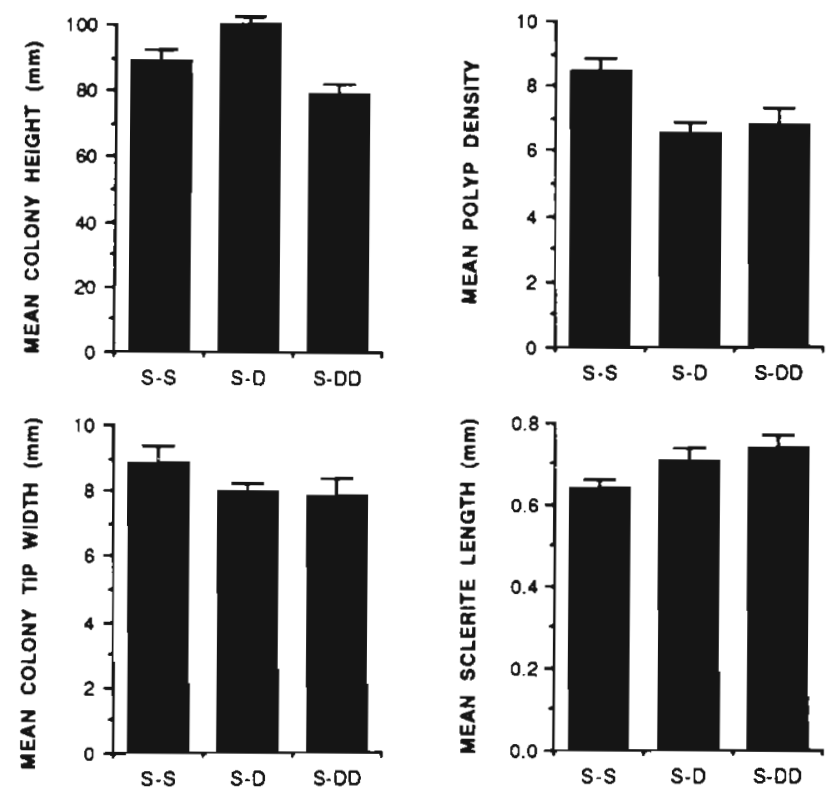

Fig. 4. Briareum asbestinum. Results of shallow colony transplantation of coral, St. Croix, U.S. Virgin Islands, final measurements. Mean + SE of colony height, colony tip width, polyp density, sclerite length. SS, SD, SDD: Shallow water coral transplanted to shallow water, deep water and very deep water, respectively

nies sampled at Chub Cay and Rum Cay, Bahamas; since it could affect total fecundity, the mean number of polyps per cross section of tissue was also measured. All traits measured for the shallow colonies significantly exceeded those measured for the deep colonies (Fig. 3). Shallow colonies possessed an average of 17.5 \pm 1.3 polyps per cross section compared to $9.6 \pm 0.2$ polyps per cross section for deep colonies (ANOVA; $F=43.739, \mathrm{p}<0.0001, \mathrm{df}=1$ ); there was an average of $1.4 \pm 0.2$ eggs per polyp for the shallow cross sections compared to $0.8 \pm 0.1$ eggs per polyp in the deep colonies (ANOVA; $F=5.862, \mathrm{p}<0.03, \mathrm{df}=1$ ). Thus, the shailow colonies produced an average of 24.5 oocytes per cross section of colony whereas the deep colonies produced an average of 7.9 oocytes per cross section of colony. In addition to the fewer eggs they produced per cross section, deeper colonies also produced smaller eggs; the average diameter of shallow eggs was $0.95 \pm$ $0.02 \mathrm{~mm}$ while deep eggs averaged $0.88 \pm 0.01 \mathrm{~mm}$ (ANOVA; $F=9.205, \mathrm{p}<0.01, \mathrm{df}=1$ ).

\section{Transplant experiment}

The initial heights of the groups of shallow colonies transplanted to 10,33 and $41 \mathrm{~m}$ as well as the reciprocally transplanted colonies did not vary among treatments (ANOVA, p > 0.3); likewise, colony tip width did not vary among treatments at the start of the experiment (ANOVA, $F=0.621, \mathrm{p}>0.45$ ).

The final heights varied significantly among treatments of shallow colonies transplanted to 3 depths (ANOVA; $F=12.417 ; \mathrm{p}<0.0001$ ): the tallest colonies were from $33 \mathrm{~m}$, intermediate were from shallow and the shortest were from $41 \mathrm{~m}$ (Fig. 4). Since this pattern of increasing, then decreasing, height with depth was contrary to our expectation, we used the more conservative, a posteriori Scheffe test for our pairwise comparisons. Both the SS and the SDD colonies were significantly shorter than the SD colonies (Scheffe; $p<0.05$ ), but the SDD colonies were not significantly shorter than the SS colonies. The final heights showed the expected pattern in the reciprocal transplant experiment: $(F=6.33 ; \mathrm{p}<0.0005$; Fig. 5). Shallow colonies transplanted deep (SD) were significantly
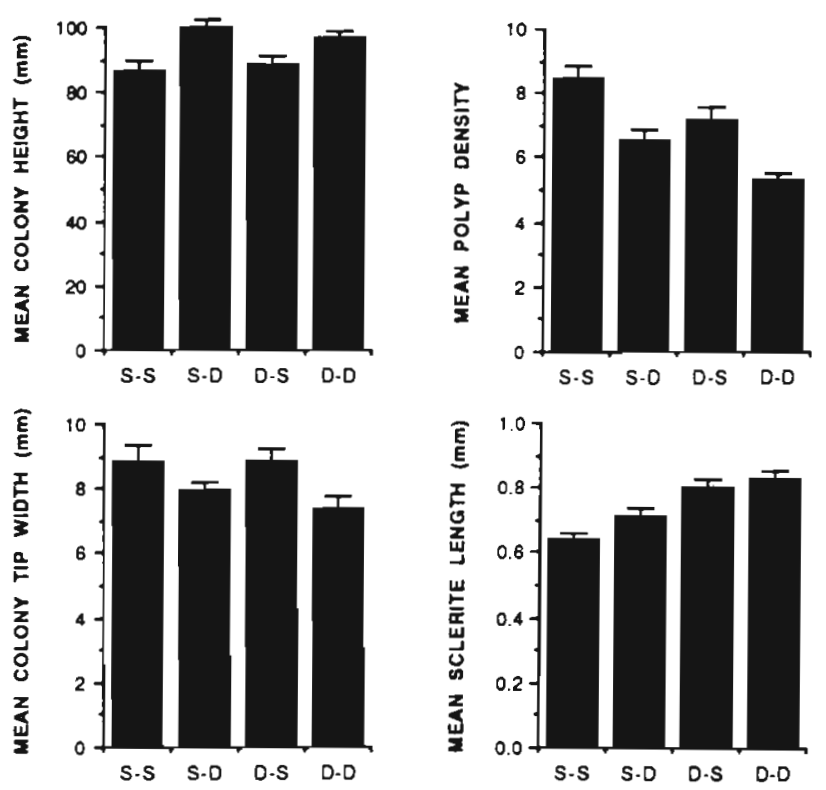

Fig. 5. Briareum asbestinum. Results of reciprocal transplantation of coral, St. Croix, U.S. Virgin Islands, final measurements. Mean + SE of colony height, colony tip width, polyp density, sclerite length. SS, SD: Shallow water coral transplanted to shallow and deep water, respectively; DS, DD: deep water coral transplanted to shallow and deep water, respectively 
taller than those remaining shallow (SS), and DD colonies were taller than DS colonies $(p<0.05$, Fisher PLSD)

The final widths did not vary significantly among treatments transplanted to 3 depths although there was a trend toward narrower tips in deeper transplants (Fig. 4, ANOVA; $F=1.799, p=0.18$ ). In the reciprocal transplant, the final tip width did vary among treatments (Fig 5, ANOVA; $F=3.694, p=0.019$ ). As expected, the SS colony tips were significantly wider than the DD tips $(p<0.05$, Fisher PLSD). The final tip widths of SD and DS colonies did not differ significantly, indicating that the transplanted colonies did not attain the same width as the native colonies. However, deep colonies moved to the shallow site (DS) became significantly wider than deep colonies remaining deep $(p<0.05$, Fisher PLSD); likewise, shallow colonies moved deep (SD) became narrower than those remaining shallow (SS), but the difference was not statistically significant. These results indicate that colonies are capable of some degree of shape change when transplanted to a different depth.

Polyp density also varied among the 3 depth treatments in the transplanted colonies (ANOVA, $F=7.75$, $p<0.003$ ). Colonies transplanted to shallow sites had significantly more polyps per $0.625 \mathrm{~cm}^{2}(8.48 \pm 0.38$ ) than those transplanted to $33 \mathrm{~m}(6.54 \pm 0.32)$ or $41 \mathrm{~m}$ $(6.81 \pm 0.46)$ (Fig. 4, Fisher PLSD, $p<0.05$ ). In the reciprocal transplant, polyp density also varied significantly among treatments (Fig. 5, ANOVA, $F=17.70$, $p<0.0001$ ). Polyp density decreased significantly between SS and SD (Fisher PLSD, $p<0.05$ ) and increased significantly between DD and DS (Fisher PLSD, $p<0.05)$. The significant difference between SD vs DD and DS vs SS (Fisher PLSD, $\mathrm{p}<0.05$ ) indicates that the transplanted colonies did not achieve the same polyp densities as the native colonies.

There was a nonsignificant trend toward increased sclerite length in the shallow colonies transplanted to the 2 deep sites relative to the shallow site (Fig. 4, ANOVA, $F=2.59, \mathrm{p}=0.087$ ). However, the sclerites of colonies remaining shallow (SS) were significantly smaller than the sclerites of the colonies transplanted to $41 \mathrm{~m}$ (SDD; Fisher PLSD, $\mathrm{p}<0.05$ ), confirming that length of sclerites is partly determined by environment. The sclerites of the colonies transplanted to $33 \mathrm{~m}$ (SD) were intermediate in length. Sclerite length also varied among treatments in the reciprocal transplant experiment (Fig. 5, ANOVA, $F=8.088, \mathrm{p}<0.002$ ). Although there was a trend for SD colonies to develop longer sclerites than SS colonies and for DS colonies to develop shorter sclerites than DD colonies (Fig. 5), the multiple comparisons tests indicate that the differences are not significant. The differences between the SS vs DS and the DD vs SD were significantly different, indi- cating that the sclerite length of these transplanted colonies did not change enough to be considered equivalent to resident colony sclerites.

\section{Artificial food assays}

In both feeding trials, Cyphoma gibbosum ate more of the food containing the smaller sclerites from shallow water than the food containing the larger sclerites from deep water. In the first trial, C. gibbosum ate 33.1 $\pm 7.8 \%$ of the food with shallow water sclerites and $14.6 \pm 4.8 \%$ of the food with the deep water sclerites (Mann Whitney $U$-test; $\mathrm{n}=15, \mathrm{p}=0.06$ ). In the second trial, C. gibbosum ate $35.0 \pm 6.1 \%$ of the shallow-sclerite and $17.6 \pm 3.9 \%$ of the deep-sclerite food (Mann Whitney $U$-test; $\mathrm{n}=24, \mathrm{p}=0.04$ ).

\section{DISCUSSION}

\section{Patterns of variation between depths}

Colonies of Briareum asbestinum from shallow sites differed from conspecifics at deep sites in morphological and life history features. Shallow-water colonies were short and stout, with more polyps per cross section and shorter sclerites. Regarding colonies as approximately cylindrical, a rough calculation using our data yielded similar mean surface areas for shallow and deep colonies. However, because the mean polyp number per unit area for the SS colonies (1.36 polyps $\mathrm{mm}^{-2}$ ) was so much greater than the mean polyp number per unit area for DD colonies ( 0.85 polyps $\left.\mathrm{mm}^{-2}\right)$, deep colonies still had, on average, $38 \%$ fewer polyps relative to shallow colonies.

Female colonies from shallow water were also distinct in having more and larger oocytes than those from deep water. The smaller oocytes of deep water colonies could have been an environmental effect due to slower development times if shallow and deep populations did not become reproductive synchronously. However, there was also a large deficit in number of oocytes per polyp that can not be attributed to a different timing of reproduction. Brazeau \& Lasker (1990) sampled the number of oocytes per polyp in female Briareum asbestinum colonies 3 times during oocyte development (from oocyte appearance in September to spawning in June 1986). They found a decrease in the number of oocytes per polyp just prior to spawning; hence, if the deep colonies that we collected were developmentally behind the shallow colonies just prior to the shallow spawning, they should have had a greater or equal number of oocytes per polyp than shallow colonies, but not fewer. 
The shallow colonies contained 1.4 oocytes per polyp compared to 0.8 oocytes per polyp for deep colonies. When combined with the greater mean polyp number per unit area, this represents a potential difference of $64 \%$ in the number of oocytes deep colonies produced relative to shallow colonies. The finding that shallow colonies produced more oocytes is not surprising since other corals have been found to display greater productivity in shallow compared to deep water (Davies 1980, McCloskey \& Muscatine 1984). Finally, none of these calculations have taken into account the fact that shallow colonies are usually more highly branched, and this should further compound the fitness advantage.

\section{Causes of variation between depths}

Final colony height varied in the transplant experiment. Among the shallow colonies transplanted to 3 depths, it was the $33 \mathrm{~m}$ transplants that ended up the tallest while the $10 \mathrm{~m}$ colonies were intermediate and the $41 \mathrm{~m}$ colonies were shortest. Direct productivity measurements confirm higher productivity rates of Briareum asbestinum in shallow water (J. Miles \& C. D. Harvell unpubl. data), so shallow colonies should grow the most. However, greater growth does not necessarily equate with greater height. Shallow colonies may increase in height more gradually than deep colonies and invest their greater energy in increasing girth and adding more, densely-packed polyps; it is also likely that shallow colonies lose more tissue as a result of predator damage. The relatively short height of the $41 \mathrm{~m}$ transplants may have resulted from lower productivity at greater depths.

The colony height data from the reciprocal portion of the transplant experiment are more easily interpreted. At the end of the experiment, the deep colonies transplanted to shallow water were nearly as short as the colonies originating in shallow water; likewise, shallow colonies that were transplanted to the deep site became almost as tall as the deep colonies originating there. Both types of deep transplants were significantly taller than their shallow counterparts, regardless of the population from which they originated. However, it must be noted that, despite the elevated design of the transplant racks to reduce predation, divers observed Hermodice carunculata (Polychaeta) preying on colonies in some of the shallow water transplant racks and rarely on the deep transplants. From these observations of the shallow and deep transplants and of wounds observed on the shallow transplants, we know that the shallow water colonies were visited and damaged by predators more often than the deeper colonies. Thus, the height data were influenced by varia- tion in both growth rates and predation rates. Since we sampled tip widths and tip sclerites only from the colonies that appeared undamaged, we do not attribute any of the changes in these features to a higher predation regime.

Colonies transplanted to a deeper site developed significantly longer sclerites and fewer polyps while colonies transplanted to a shallower site showed no change in sclerite length but became thicker and developed more polyps. Since the transplant experiment ran for 6 mo (including part of the peak, summer growing season), and since Briareum asbestinum can grow up to $13 \mathrm{~cm} \mathrm{yr}^{-1}$ (Brazeau 1989), we considered this sufficient time for the growth of new tissue for analysis. In some characters such as the sclerites and whole colony tip width, the induced form did not always reach the same value as the resident form. This suggests that, in addition to an environmental component to colony morphology, there may also be either a genetic component that is specific to particular depths or a decrease in the potential plasticity of colonies with age. Indeed, our electrophoretic work with $B$. asbestinum in the Bahamas indicates significant genetic differences between shallow and deep populations although not to a degree indicative of separate species (Brazeau \& Harvell unpubl.).

\section{Consequences of variation between depths}

The adaptive nature of some of the changes in morphology is uncertain. The reduction of polyp density and colony thickness on deep reefs may be considered adaptations to a reduced light regime. On deeper reefs, with lower light, dense polyps can self-shade and actually reduce carbon fixation rates; similarly, thicker colonies are also more likely to self-shade. In the same way that reduced light in deep water imposes constraints on form, so might increased water motion on shallow reefs. Tall, thin colonies from deep water are probably susceptible to breakage and may be too fragile to survive in many shallow environments.

The variation in sclerite form is likely to affect both susceptibility to predation and breakage by wave force. Our experiments with Cyphoma gibbosum demonstrate that the longer sclerites of deep water colonies are more deterrent, confirming a hypothesis proposed earlier (Koehl 1982, Harvell \& Suchanek 1987). However, the adaptive basis for these changes is difficult to interpret since we have shown that the longer, deep water sclerites actually function better as predator deterrents, and there are far fewer invertebrate predators in deep water than in shallow water (Harvell et al. 1993). Sclerites almost certainly do have multiple functions as predator deterrents and also as stiffening 
agents in soft gorgonian tissue. We suggest that smaller sclerites are favored in the cortex of shallow water colonies because they contribute to stiffer colony form; stiffness of soft tissues such as coral coenenchyme is a function of the surface area of the stiffening particles added, and smaller sclerites carry a higher per area stiffening potential (Koehl 1982). We see no adaptive value associated with the larger sclerites developed in the cortex of the deep water colonies and suggest that these are formed as a consequence of a slower growth rate due to a reduced light regime.

Acknowledgements. This work was supported by NSF OCE9012034 to C.D.H. and NOAA 89-1 to C.D.H. and J. Miles. We appreciate use of laboratory facilities at West Indies Laboratory and ship support from NSF (through CHE 8620217 to William Fenical). We are grateful for diving assistance in the field from C. Greene, J. Nowlis, B. Helmuth, C. Lennert. We also owe thanks to the entire 'Aquarius' crew for their assistance during our NOAA mission, particularly to D. Kesling for help with diving and underwater video technology. The manuscript benefitted from the comments of 3 anonymous reviewers

\section{LITERATURE CITED}

Antonovics, J. (1976). The nature of limits to natural selection. Ann. M. bot. Gard. 63: 224-247

Bayer, F. M. (1961). The shallow water octocorallia of the West Indian region. Nijhoff, The Hague

Brazeau, D. A. (1989). A male-biased sex ratio in the Caribbean octocoral, Briareum asbestinum: sex ratio evolution in clonal organisms. Ph.D. dissertation, State University of New York, Buffalo

Brazeau, D. A., Lasker, H. R. (1990). Sexual reproduction and external brooding by the Caribbean gorgonian Briareum asbestinum. Mar. Biol. 104: 465-474

Briggs, D., Walters, S. M. (1988). Plant variation and evolution 2nd edn. Cambridge University Press, Cambridge

Davies, P. S. (1980). Respiration in some Atlantic reef corals in relation to vertical distribution and growth form. Biol. Bull. 158: $187-194$

de Weerdt, W. H. (1981). Transplantation experiments with Caribbean Millepora species, including some ecological observations on growth forms. Bijdr. Dierk. 51: 1-9

This article was submitted to the editor
Dustan, P. (1979). Distribution of zooxanthellae and photosynthetic chloroplast pigments of the reef-building coral Montastrea annularis in relation to depth on a West Indian coral reef. Bull. mar. Sci. 29: 79-95

Foster, A. B. (1980). Environmental variation in skeletal mophology within the Caribbean reef corals Montastrea annularis and Siderastrea siderea. Bull. mar. Sci. 30: $678-709$

Harvell, C. D., Suchanek, T H. (1987). Partial predation on tropical gorgonians by Cyphoma gibbosum (Gastropoda). Mar. Ecol. Prog. Ser. 38: 37-44

Harvell, C. D., Fenical, W., Roussis, V., Ruesink, J. L., Griggs, C. M., Greene, C. H. (1993). Local and geographic variation in the defensive chemistry of a West Indian Gorgonian coral (Briareum asbestinum). Mar. Ecol. Prog. Ser. 93: 165-173

Hay, M. E., Goertemiller, T. (1983). Between-habitat differences in herbivore impact on Caribbean coral reefs. In: Reaka, M. L. (ed.) The ecology of deep and shallow coral reefs. Symposia for Underseas Research, Vol. I. Office of Undersea Research, NOAA, Rockville, MD, p. 97-102

Hay, M. E., Colburn, T., Downing, D.. (1983). Spatial and temporal patterns in herbivory on a Caribbean fringing reef: the effects on plant distribution. Oecologia 58: 299-308

Jackson, J. B .C., Cheatham, A. H. (1990). Evolutionary significance of morphospecies: a test with Cheilostome Bryozoa. Science 248: 579-582

Kinzie, R. A. III (1971). The ecology of the gorgonians (Cnidaria, Octocorallia) of Discovery Bay, Jamaica. Ph.D. dissertation, Yale University, New Haven

Knowlton, N., Weil, E., Weight, L. A., Guzman, H. M. (1992). Sibling species in Montastrea annularis, coral bleaching and the coral climate record. Science 255: 330-333

Koehl, M. A. R. (1982). Mechanical design of spicule-reinforced connective tissue: stiffness. J. exp. Biol. 98: 239-267

McCloskey, L. R., Muscatine, L. (1984). Production and respiration in the Red Sea coral Stylophora pistillata as a function of depth. Proc. R. Soc. Ser. B 222: 215-230

Miles, J. (1991). Inducible agonistic structures in the tropical corallimorpharian, Discoma sanctithomae. Biol. Bull. 180: 405-415

Vernon, J. E. N., Pichon, M. (1976). Scleractinia of eastern Australia, Vol. 1. Australian Government Printing Office, Canberra

Wijsman-Best, M. (1974). Habitat-induced modification of reef corals (Faviidae) and its consequences for taxonomy. Proc. 2nd int. coral Reef Symp. 2: 217-228

Manuscript first received: June 11, 1992

Revised version accepted: December 17, 1992 